\title{
GREATER SEVERITY OF CLINICAL FEATURES IN OLDER PATIENTS WITH DUANE'S RETRACTION SYNDROME
}

\author{
CARMEL P. NOONAN and MARTIN O'CONNOR \\ Dublin, Ireland
}

\begin{abstract}
SUMMARY
Duane's retraction syndrome (DRS) is a well-described entity. However, the possibility of this condition having progressive features has not been previously documented. We studied 21 consecutive patients with this disorder and found that the incidence of severe retraction on adduction, the occurrence of enophthalmos in the primary position and the presence of upshoots and downshoots were significantly higher in adults with type I DRS than in children. A wareness that the clinical features may increase in severity is important as parental counselling, coupled with effective communication to general practitioners, can prompt re-referral should such problems arise. Surgical intervention as a consequence, becomes an available option to correct disease progression.
\end{abstract}

Duane's retraction syndrome (DRS), described by Duane in 1905, is a congenital eye movement disorder characterised by: (1) limitation of abduction, (2) partial deficiency in adduction, (3) retraction of the globe and palpebral narrowing on attempted adduction, (4) upshoots and downshoots on adduction and (5) deficiency of convergence. ${ }^{1}$ Until the advent of electromyography Duane's retraction syndrome was attributed to replacement of the normal contractile lateral rectus muscle by fibrous tissue. Neuropathological studies, however, have shown that the abducent nucleus is absent or hypoplastic, and that the lateral rectus is innervated by branches of the inferior division of the oculomotor nerve. ${ }^{2,3}$ Electromyography (EMG) and saccadic velocity studies on DRS have confirmed abnormal innervation of the lateral rectus, leading to co-contraction with the medial rectus on attempted adduction. ${ }^{4-6}$

From: Royal Victoria Eye and Ear Hospital, Dublin, Ireland. Correspondence to: Carmel P. Noonan, St Paul's Eye Unit, Royal Liverpool University Hospital, Prescot Road, Liverpool L7 8XP, UK.
Controversy surrounds the aetiological mechanisms underlying the upshoots and downshoots in this disorder. The 'bridle' or 'leash' phenomenon theory suggests that these effects are produced by a tight lateral rectus muscle slipping over or under the globe on adduction. This is borne out by the variety of surgical techniques on the lateral rectus muscle (i.e. recession, posterior fixation suture or the splitting of the muscle into a $\mathrm{Y}$ configuration plus recession) which are successful in eliminating or decreasing the upshoot or downshoot. ${ }^{7-12}$ In some cases there may also be a true anomalous innervation of the cyclovertical muscles. ${ }^{13}$ EMG studies have shown co-contraction of the superior rectus with the lateral rectus in some patients with upshoots, and this has been further confirmed in recent magnetic resonance imaging (MRI) studies., ${ }^{5,14}$

Numerous reports document the clinical features and surgical management in DRS. ${ }^{15-17}$ However, limited attention has focused on the possibility that retraction, upshoots, downshoots and enophthalmos may progress insidiously in patients as they grow older. In this study we outline clinical features in a consecutive series of patients with DRS and propose a clinical index to grade disease severity that supports the concept of this disorder having progressive features.

\section{METHODS}

All patients on our records who attended the orthoptic department between 1960 and 1991 with Duane's retraction syndrome were contacted to participate in the study. Of 24 patients contacted, 21 were available for study, representing a response rate of $87.5 \%$. The other 3 patients had moved from the region and were uncontactable. We estimated that this study population represented some $55 \%$ of patients with DRS on whom a detailed index registry was maintained. All patients were initially referred as children from their general practitioner, or following

Eye (1995) 9, 472-475 C 1995 Royal College of Ophthalmologists 


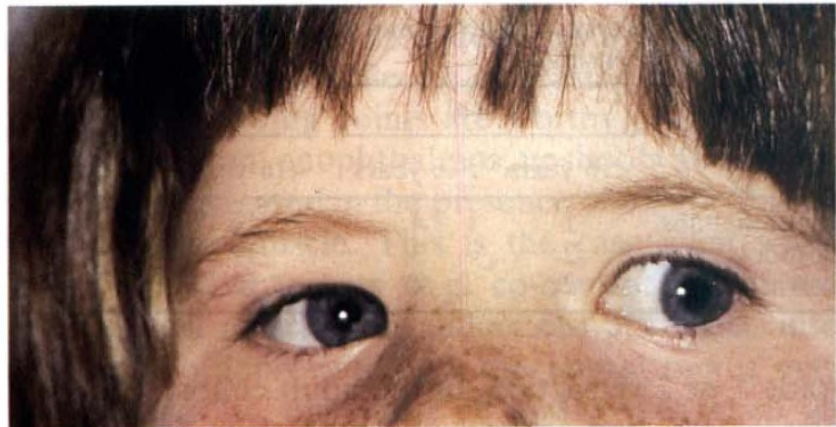

Fig. 1. Right Duane's syndrome with grade 1 retraction.

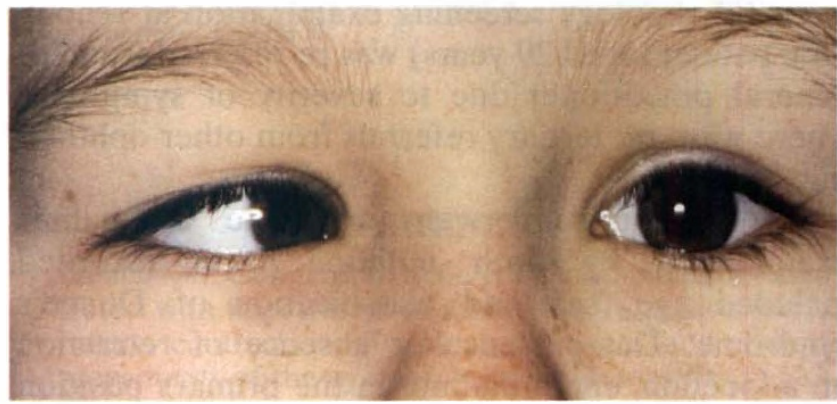

Fig. 2. Bilateral Duane's syndrome with grade 2 retraction in the right eye.

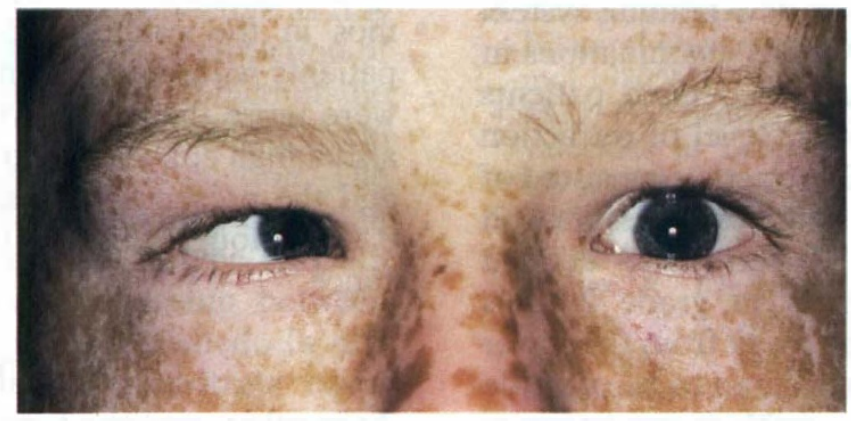

Fig. 3. Bilateral Duane's syndrome with grade 3 retraction in the right eye.

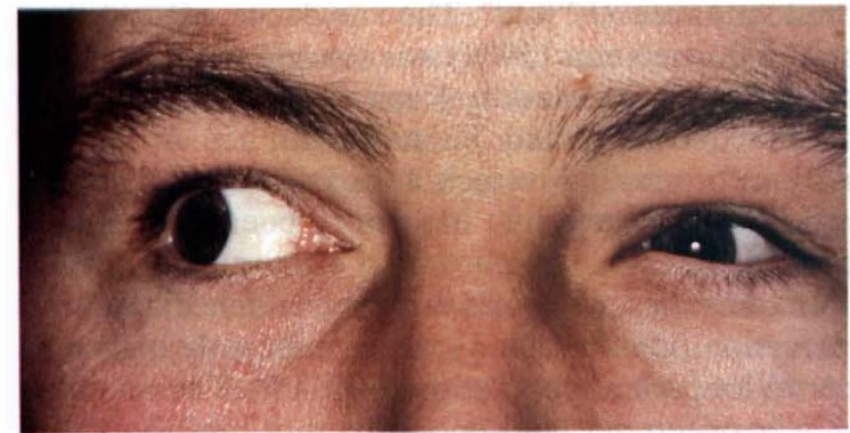

(a)

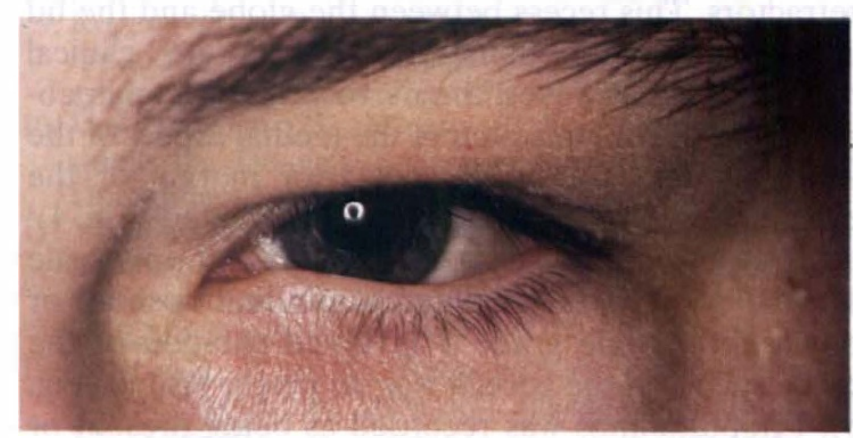

(b)

Fig. 4. Left Duane's syndrome with grade 4 retraction. Note the eversion of the left lower lid with recess between the lid and the globe.

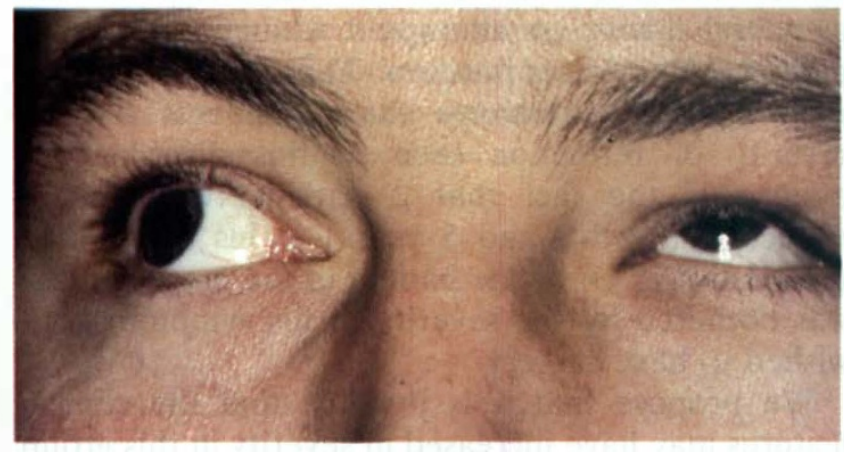

Fig. 5. Left Duane's syndrome with grade 2 upshoot on adduction.

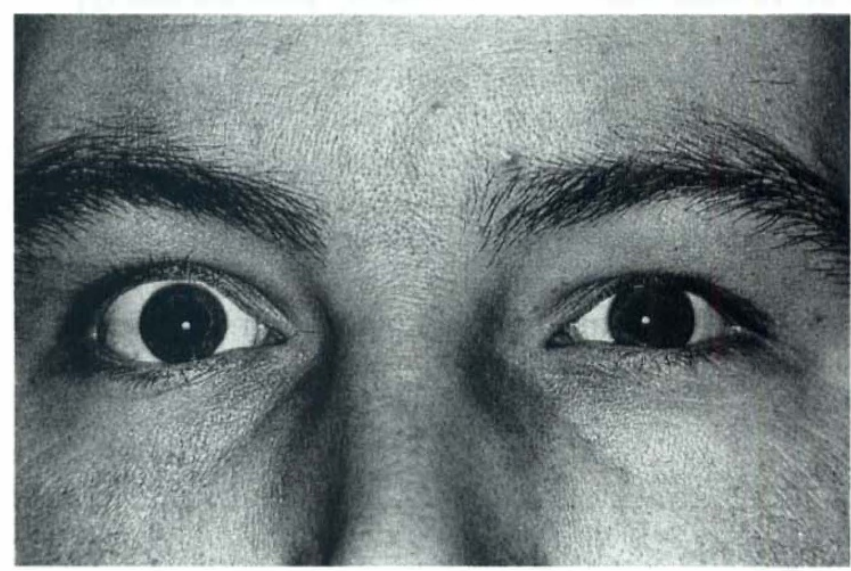

Fig. 6. Enophthalmos in the primary position. 
an ophthalmology screening examination at school. One patient (aged 29 years) was re-referred from his general practitioner due to severity of symptoms. There were no tertiary referrals from other ophthalmic centres.

All patients underwent complete ophthalmic examination by both authors. Data recorded included age, sex and classification of Duane's syndrome. The presence or absence of retraction on adduction, enophthalmos in the primary position and upshoots and downshoots in adduction were noted. In order to quantitate the severity of retraction, an arbitrary clinical severity score of +1 to +4 was developed. This is a new grading system and had not been used in previous examinations in these patients. Grade 1 retraction defined patients who had an almost imperceptible level of retraction on adduction (Fig. 1). Grade 2 retraction consisted of further narrowing of the palpebral fissure on adduction (Fig. 2). Grade 3 retraction defined patients who had retraction as in grade 2, plus minimal retraction of the globe away from the lower lid (Fig. 3). Retraction was considered to be of grade 4 severity if there was a clearly visible recess between the globe and the lower lid, which also had, in some instances, an associated contraction of the lower lid retractors. This recess between the globe and the lid is difficult to demonstrate on routine clinical photography; however, the narrowing of the palpebral fissure, the contraction of the medial aspect of the lower lid and the visible posterior margin of the everted lower lid can be readily appreciated (Fig. 4).

Upshoots and downshoots were graded on a scale of 0 to +3 . Grade 1 defined a minimal upshoot or downshoot, while grade 3 involved rotation of the globe such that the cornea was no longer visible (Fig. $5)$. Enophthalmos was recorded as being present or absent (Fig. 6).

\section{RESULTS}

Of the 21 patients examined, 11 were female $(52 \%)$ and 10 were male (48\%). Twenty patients had type I DRS and 1 patient had type II DRS. Eleven patients $(52 \%)$ had a left Duane's syndrome, 5 patients had a right Duane's and 5 patients had bilateral Duane's. Amblyopia was found in 3 patients (14\%).

All patients had retraction (Table I). A positive correlation was found between patient age and increasing severity of retraction $(r=0.68 ; p<0.005)$. Of the 21 patients, $85 \%$ younger than 16 years had

Table I. Number of eyes and grade of retraction

\begin{tabular}{lcc}
\hline Retraction & $\begin{array}{c}<16 \text { years } \\
(14 \text { eyes })\end{array}$ & $\begin{array}{c}>16 \text { years } \\
(12 \text { eyes })\end{array}$ \\
\hline Grade 1 & 6 & 3 \\
Grade 2 & 6 & 3 \\
Grade 3 & 2 & 4 \\
Grade 4 & 0 & 2 \\
\hline
\end{tabular}

Table II. Age versus incidence and severity of enophthalmos, upshoots and downshoots

\begin{tabular}{lcccccc}
\hline & \multicolumn{2}{c}{ Present } & & \multicolumn{2}{c}{ Absent } \\
\cline { 2 - 3 } \cline { 5 - 6 } & $<16$ years & $>16$ years & & $<16$ years & $>16$ years \\
\hline Enophthalmos & 1 & 4 & & 13 & 8 \\
Upshoots & 2 & 3 & & 12 & 9 \\
Downshoots & 2 & 4 & & 12 & 8 \\
\hline
\end{tabular}

grade 1 or 2 retraction. In the adult cohort (i.e. $\geqslant 16$ years), $50 \%$ had grade 1 or 2 retraction. In patients with grade 3 or 4 retraction, $75 \%$ were more than 16 years old.

Severe retraction was associated with enophthalmos in the primary position. Eighty per cent of patients with enophthalmos in the primary position were more than 16 years old (Table II). There was also a high correlation found between increasing age and the presence of upshoots and downshoots $(r=$ 0.8 ), although this did not reach statistical significance.

\section{DISCUSSION}

As in other published series on DRS, type I DRS was seen more frequently, the left eye was affected in $52 \%$ of patients and there was a small female predominance $(52 \%) .{ }^{14}$ The incidence of upshoots and/or downshoots (39\%) was somewhat higher than in the series reported by Raab $(25 \%)$ but similar to that of Isenberg and Urist $(38 \%) .{ }^{16,17}$ A scoring system for grading retraction in DRS and quantitating disease severity has not been previously described.

In our series, we found that the incidence of severe retraction (i.e. $\geqslant$ grade 3 ) was significantly higher in our older patient population $(p<0.005)$. The relationship between age and enophthalmos, upshoots and downshoots, although highly correlated, was not found to be significant. Of the patients with type I DRS, $35 \%$ had retraction $\geqslant$ grade 3 and $70 \%$ of these patients were older than 16 years of age. The only patient in our series with type III DRS had grade 3 retraction (aged 12 years). $\mathrm{Kraft}^{8}{ }^{8}$ reporting on the surgical management and outcome of DRS, defined severe retraction as 'a $50 \%$ narrowing of the palpebral fissure on attempted adduction, as compared to the primary position'. This is one of the few reports in the literature that comments on the severity of retraction seen in this disorder. Of interest is the fact that 2 patients with severe retraction (aged 3 and 6 years) in his report had type II DRS.8 Only one patient in the present study was bothered by the severity of his symptoms and wished to have surgery.

We propose that it is possible that the clinical features may have increased in severity in this group of patients with type I DRS. In order to identify whether this is true progression, prospective studies 
are needed. In order to understand the pathophysiology that may underlie the increasing retraction in DRS, the following points are worthy of consideration. Retraction, enophthalmos, upshoots and downshoots are increased in the presence of a tight fibrotic lateral rectus muscle. This is the case even when other causative factors (e.g. co-contraction of the cyclovertical muscles on adduction) are taken into account. To appreciate how the lateral rectus may become fibrotic, one must be aware that when an imbalance between an agonist-antagonist muscle pair exists, stiffness may develop in the greater of the two muscle forces with time. In type II DRS the contraction of the medial rectus is ineffective as it is counterbalanced by an equally strong contraction of the lateral rectus on adduction. On abduction the lateral rectus is unopposed and activates a normal number of motor units to achieve abduction. The lateral rectus is the stronger force and thus as a result may contract with time. In contrast, in type III DRS the usual agonist-antagonist relationship between the two muscles is completely abolished. In the primary position both muscles demonstrate equal innervation, which is maintained on attempted adduction. If a patient with type III DRS is exotropic in the primary position, then the lateral rectus is the stronger of the two muscles and may become a tight fibrotic muscle and vice versa. Finally, in type I DRS the lateral rectus muscle co-contracts with the medial rectus muscle, and it thus depends on the delicate balance of forces between the two muscle pairs as to which of them will become fibrotic. Contracture of the medial rectus has been reported in some patients with type I DRS who have an esotropia in the primary position and a compensatory head turn. ${ }^{7}$ We suggest that as the imbalance in type I DRS is less than that in types II and III, severe retraction may be seen less commonly in younger patients.

In summary, this study has found that the incidence of severe retraction is significantly higher in adult patients with type I DRS. This does not necessarily imply a need for surgery; however, when symptoms are particularly severe, surgery has a definite role to play. In view of the present findings we suggest that effective communication to parents and family practitioners regarding the nature of this phenomenon can hasten surgical intervention and obviate disease progression.
Key words: Downshoots, Duane's retraction syndrome, Enophthalmos, Upshoots.

\section{REFERENCES}

1. Duane A. Congenital deficiency of abduction associated with impairment of adduction, retraction movements, contraction of palpebral fissure and oblique movements of the eye. Arch Ophthalmol 1905;34:13359.

2. Miller NR, Kiel SM, Green WR, Clark AW. Unilateral Duane's retraction syndrome (type I). Arch Ophthalmol 1982;100:1468-72.

3. Hotchkiss MG, Miller NR, Clarke AW, Green WR. Bilateral Duane's retraction syndrome. Arch Ophthalmol 1980;98:870-4.

4. Metz HS, Scott AB, Scott WE. Horizontal saccadic velocities in Duane's syndrome. Am J Ophthalmol 1975;80:901-6.

5. Scott AB, Wong GY. Duane's syndrome: an electromyographic study. Arch Ophthalmol 1972;87:140-7.

6. Huber A. Electrophysiology of the retraction syndromes. Br J Ophthalmol 1974;58:293-300.

7. Jampolsky A. Surgical leashes and reverse leashes in strabismus surgical management. In: Symposium on strabismus. Transactions of the New Orleans Academy of Ophthalmology. St Louis: CV Mosby, 1978:244-53.

8. Kraft SP. A surgical approach for Duane syndrome. J Pediatr Ophthalmol Strabismus 1988;25:119-30.

9. Rogers GL, Bremer DL. Surgical treatment of upshoots and downshoots in Duane's retraction syndrome. Ophthalmology 1984;91:1380-3.

10. Von-Noorden GK, Murray E. Upshoots and downshoots in Duane's retraction syndrome. J Pediatr Ophthalmol Strabismus 1986;23:212-5.

11. Von-Noorden GK. Recession of both horizontal recti in Duane's retraction syndrome with elevation and depression of the adducted eye. Am J Ophthalmol 1992;114:311-3.

12. Scott AB, Wong G, Jampolsky A. Pathogenesis in Duane's syndrome [abstract]. Invest Ophthalmol Vis Sci 1970;9:983.

13. Lee JP. Congenital extraocular muscle defects. Eye 1992;6:181-3.

14. Bloom JN, Graviss ER, Mardelli PG. A magnetic resonance imaging study of upshoot-downshoot phenomenon of Duane's retraction syndrome. Am J Ophthalmol 1991;111:548-54.

15. O'Malley ER, Helveston EM, Elis FD. Duane's retraction syndrome - plus. J Pediatr Ophthalmol Strabismus 1982;19:161-5.

16. Raab EL. Clinical features of Duane's syndrome. J Pediatr Ophthalmol Strabismus 1986;23:64-8.

17. Isenberg S, Urist MJ. Clinical observations in 101 consecutive patients with Duane's retraction syndrome. Am J Ophthalmol 1977;84:419-25. 